\title{
Malaria elimination in Lao PDR: the challenges associated with population mobility
}

Sengchanh Kounnavong ${ }^{1 *}$, Deyer Gopinath², Bouasy Hongvanthong ${ }^{3}$, Chanthalone Khamkong ${ }^{3}$ and Odai Sichanthongthip ${ }^{3}$

\begin{abstract}
Although the Lao People's Democratic Republic (Lao PDR) is comparatively small landlocked country with patterns of both in- and out-migration, its human migration situation has been poorly studied. This is despite all of the country's 18 provinces sharing both official and unofficial border checkpoints with neighboring countries. Economic reforms in the last decade have seen a gradual increase in the promotion of foreign investment, and main towns and transportation networks have been expanding thus offering new opportunities for livelihoods and economic activities.

In the last decade, there has also been a significant reduction of reported malaria cases in Lao PDR and while this is an important prerequisite for eliminating malaria in the country, malaria outbreaks reported in the last four years suggest that population mobility, particularly in the south, is an important factor challenging current control efforts.

Bolder investment in social sector spending should be geared towards improving health service provision and utilization, ensuring equitable access to primary health care (including malaria) through efforts to achieve universal health coverage targets. This should be extended to populations that are mobile and migrants. The local government plays a critical role in supporting policy and enforcement issues related to private sector project development in the provinces. Cross-border initiatives with neighboring countries, especially in terms of data sharing, surveillance, and response, is essential. Mechanisms to engage the private sector, especially the informal private sector, needs to be explored within the context of existing regulations and laws. Existing and new interventions for outdoor transmission of malaria, especially in forest settings, for high-risk groups including short- and long-term forest workers and their families, mobile and migrant populations, as well as the military must be combined into integrated packages with innovative delivery mechanisms through social marketing approaches. This should happen at multiple points in the mobility pathway and involve the private sector rather than being fully reliant on the national malaria vertical program This article based on the review of existing literature from abstracts and full texts, includes published, peer-reviewed English language literature sourced through PubMed and grey literature sources through Google and Google Scholar. The review included also case reports, sector reports, conference proceedings, research reports, epidemiology studies, qualitative studies, and census reports in both Lao and English languages. The authors used the search terms: malaria and mobile populations, malaria control program and elimination, health system performance, malaria outbreak, Lao PDR; and included articles published until June 2015.
\end{abstract}

Keywords: Malaria, Malaria control program, Malaria elimination, Malaria outbreak, Migrants, Mobile populations, Lao PDR

\footnotetext{
* Correspondence: sengchanhkounnavong@hotmail.com

${ }^{1}$ National Institute of Public Health, Ministry of Health, Ban Kaognot, Samsenthai Road, Sisattanak District, Vientiane, Lao PDR

Full list of author information is available at the end of the article
}

\section{Biomed Central}

(c) The Author(s). 2017 Open Access This article is distributed under the terms of the Creative Commons Attribution 4.0 International License (http://creativecommons.org/licenses/by/4.0/), which permits unrestricted use, distribution, and reproduction in any medium, provided you give appropriate credit to the original author(s) and the source, provide a link to the Creative Commons license, and indicate if changes were made. The Creative Commons Public Domain Dedication waiver (http://creativecommons.org/publicdomain/zero/1.0/) applies to the data made available in this article, unless otherwise stated. 


\section{Multilingual abstract}

Please see Additional file 1 for translation of the abstract into the five official working languages of the United Nations.

\section{Background}

Malaria transmission varies across the different ecological zones of Lao People's Democratic Republic (Lao PDR). The majority of high transmission areas are hilly, forested areas in the southern part of the country where the majority of people are employed in forest-related occupations [1]. Lower rates of transmission are recorded in the plains along the Mekong River and in high altitude areas. Between 2002 and 2012, the number of suspected (showing clinical symptoms) and confirmed malaria cases, and the number of malaria-related deaths fell by 46\% (from 85192 to 46 153) and 77\% (from 195 to 44), respectively [2]. However, these gains have been threatened by a large-scale resurgence in the southern half of the country beginning in 2011, with more than 50000 confirmed cases reported nationally in 2014 [2].
The national annual parasite incidence (API) in 2011 was 2.66 per 1000 population, but rose to 7.3 in 2014, with the subnational API in the five southern provinces reaching 20.3 per 1000 [2]. This resurgence was focused in Savannakhet, Saravan, Sekong, Attapeu, and Champasak, collectively accounting for $96 \%$ of the total cases in 2014 . However, over the same period, the northern half of the country has made rapid progress towards subnational elimination goals, recording 708 cases (API of 0.21) in 2014. Out of a total population of almost seven million, approximately $36 \%$ live in high transmission areas (API $>1$ per 1000$), 23 \%$ live in low transmission areas (API $<1$ ), and the remaining $41 \%$ live in malaria-free areas [ibid] (see Fig. 1).

\section{Malaria in mobile and migrant populations (MMPs)}

Population groups at risk of acquiring malaria in endemic areas of Lao PDR include both static and mobile populations [2]. The malaria outbreaks in the last five years have been attributed to a number of factors including unregulated deforestation, deforestation related to large-scale

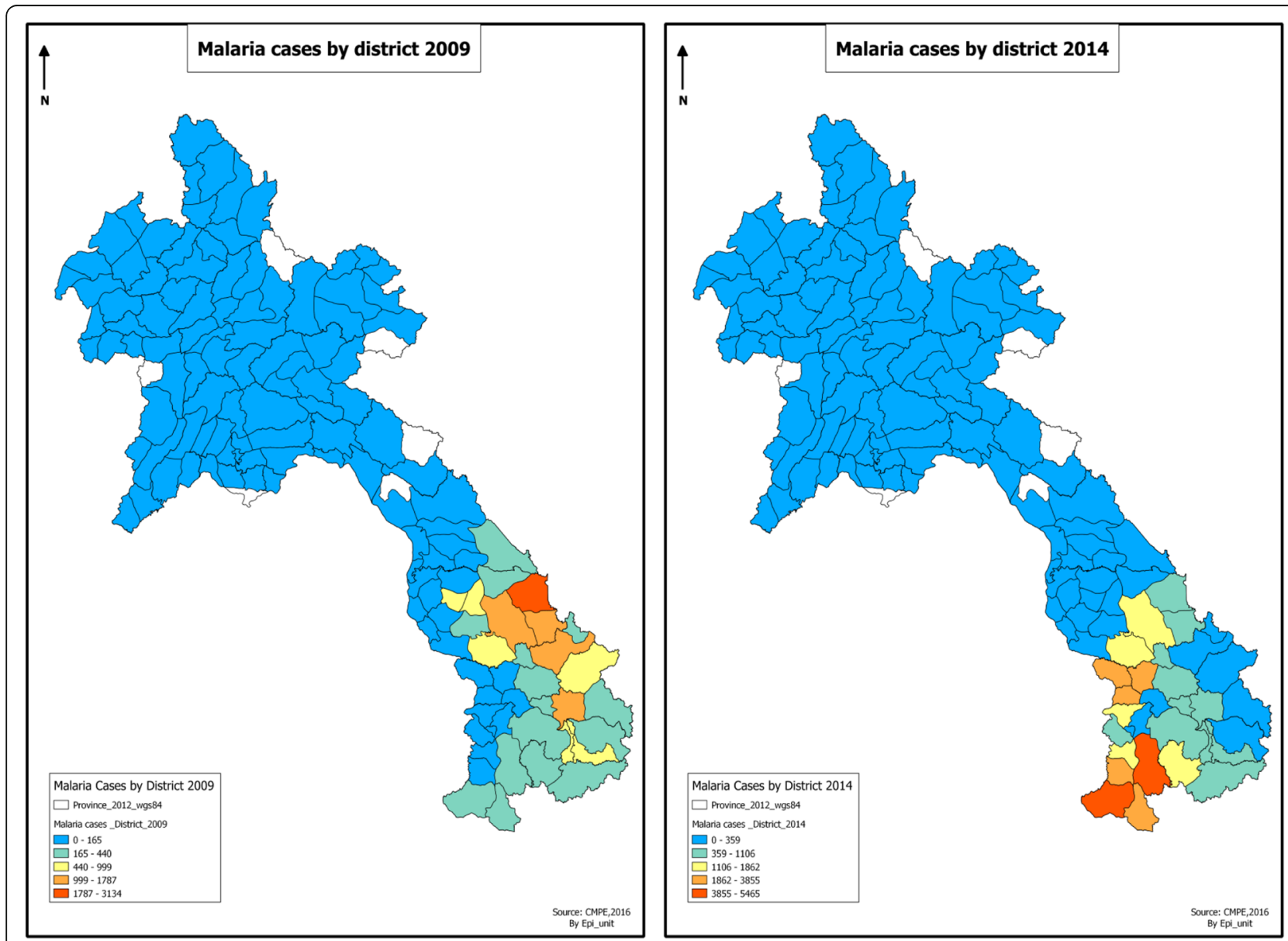

Fig. 1 Lao Peoples Democratic Republic: Confirmed malaria cases by district in 2009 and 2014. Confirmed malaria cases in 2009 and 2014 in Lao PDR, by district 
development projects (the construction of hydropower dam, roads, mining, plantations, etc.), migration of workers from non-endemic areas, and possibly climatic conditions (rainfall patterns, temperature, and humidity) $[3,4]$. However, it is believed that large-scale population movements (both within Lao and across national borders) as well as forest-related economic activities have primarily driven this resurgence of malaria; the vast majority of reported cases (86\% in 2014) were adult males. Migrant workers (both registered and unregistered) from neighboring countries employed on development projects in Lao PDR are also at high risk of acquiring malaria, but cases from these groups until 2015 were not routinely captured through the malaria information system (MIS). An assessment of a malaria outbreak in Attapeu in 2011 showed that migrant workers, both from other provinces in Lao PDR and neighboring countries, accounted for approximately $70 \%$ of confirmed malaria cases [Deyer G. Brief report on malaria outbreak in the Southern part of Lao PDR. December 2012. Unpublished reports for CMPE and WHO, 3]. The hydropower dam projects in Attapeu involved an estimated 4 000-5 000 workers at the peak of the construction phase in 2012, the majority of whom were Vietnamese and Chinese nationals [CMPE. Malaria Outbreak in Attapeu Province: November - December
2011, Investigation Report, unpublished. 2011] (see Fig. 2). Although control measures were taken, the number of cases did not drop (as of late 2014) to the seasonal low levels seen prior to 2011. However, preliminary findings of a survey conducted by Health Poverty Action [5] in 2015 show that of the 186 mobile and migrant workers interviewed in parts of southern Lao PDR, 66\% were Lao while $31 \%$ were Vietnamese and the rest were from China, Cambodia, and Thailand, the majority (70\%) of whom were adult males. In this group, 85\% (158/186) had a blood test of whom $71 \%$ tested positive for malaria. In the northern and central provinces, focal outbreaks over 2011-2015 revealed, through outbreak investigations, that causation of the outbreaks was mostly due to resident mobile workers in the northern provinces with relatively low immunity returning from the endemic southern provinces of Attapeu, Champasack, Sekong and Saravanh [4].

\section{Economic development and changing land use}

Lao PDR's economy grew to $8.1 \%$ in 2013 resulting in the World Bank declaring that the country has a fastgrowing economy. There has been an average $7 \%$ gross domestic product growth over the last two decades, the highest growth rate in Southeast Asia. The country's population is projected to increase by $27 \%$ from 6.4

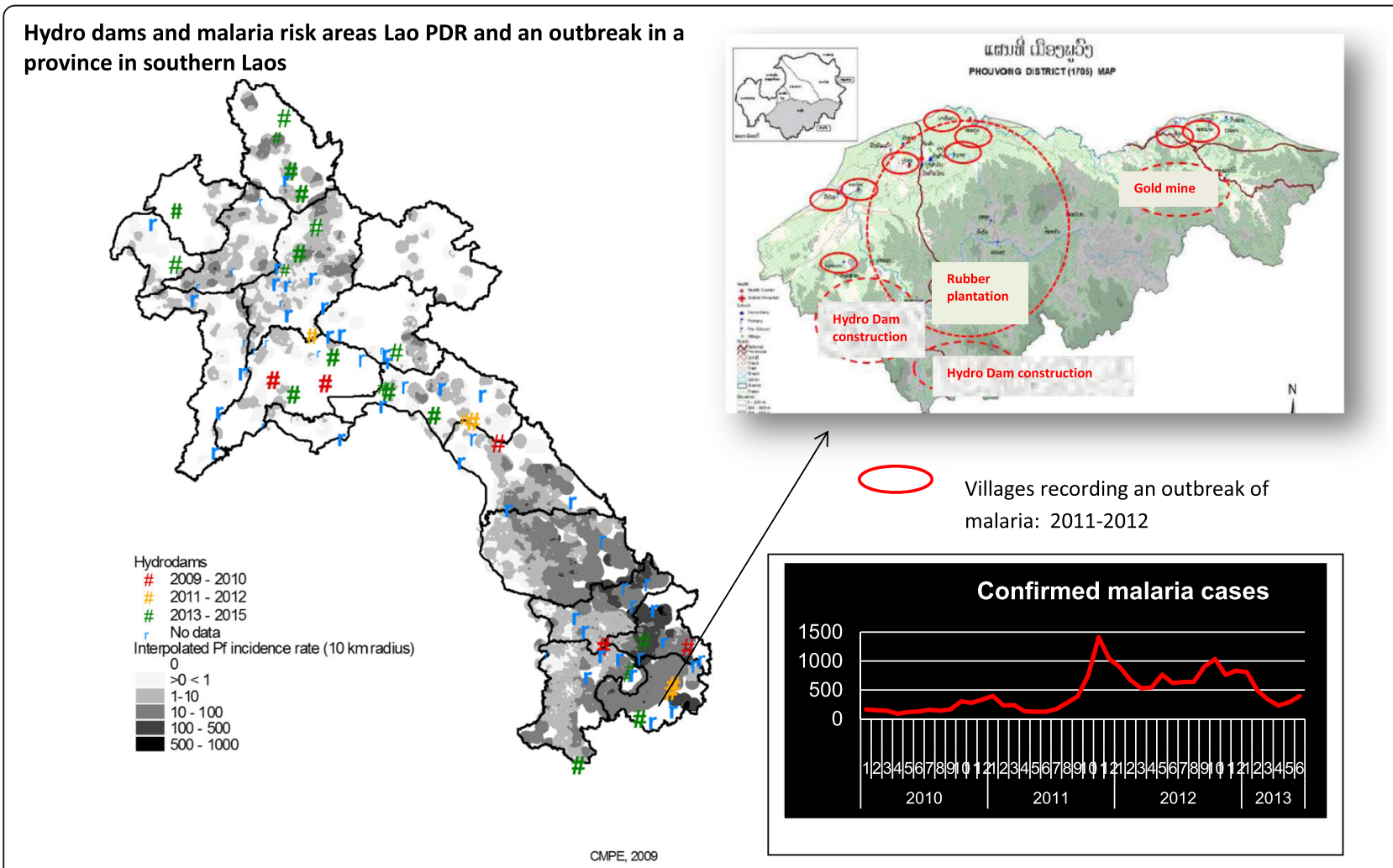

HD Source: MRC, Vientiane, Lao PDR, September 2008 Pf incidence: CMPE 2008

Fig. 2 Hydro dams and malaria risk areas in Lao PDR: an outbreak in a province in southern Laos 
million in 2010 to 8.8 million in 2030, and it is predicted to achieve its long-term goal of graduating from its 'least developed country' status by 2020 [6]. The major contributors to this growth have been the service, mining, hydropower, construction, and food processing industries [ibid], with plans for further expansion in these sectors. As of 2014, a total of 53 hydropower dam projects (signed memorandum of understandings and project development agreements) have been initiated, with 30 of these in the south [7] where malaria is prevalent. In the fiscal year of 2013-2014, the mining industry earned 12.56 trillion LAK (1.56 billion USD) from exports, with the Ministry of Energy and Mining granting licenses to 69 companies operating projects on a total area of 274 663 ha [8]. A recent study showed that almost one third of all land concessions and leases granted involve land categorized as forests. In addition, $23 \%$ of all land under investment is categorized as protection forest [9]. While it is currently estimated that 7 out of 10 workers in Lao PDR are engaged in agriculture, it is predicted that 96 000 young people will be looking for jobs annually in the coming decades, which would greatly influence population mobility both across rural and urban areas, and across borders [10].

\section{Human migration patterns}

Rural infrastructure development may bring non-immune people into endemic areas [11], and increase mobility among local surrounding populations and among nonmobile populations in villages to which migrants periodically return [2]. The Asian Highway and Greater Mekong Subregion (GMS) economic corridors that cut through endemic areas in GMS countries and extensively in Lao PDR [12,13] will mean that an increasing number of people and possibly malaria parasites will move between localities with different malaria endemicity and risks of malaria transmission [14]. In addition to planned development activities, unregulated economic activities such as logging related to constructions of dams particularly in the southern provinces pose challenges for vector control and protection measures, and for prompt detection and treatment of infected cases. Many people when febrile or sick also prefer to return to their home provinces thus increasing the possibility of severe malaria complications and possible death due to delayed treatment [4].

Although all 18 provinces of Lao PDR are bordered with GMS countries, the out-migration patterns are not significantly higher near the borders highlighting that geographical proximity of other countries does not seem to be the most crucial factor stimulating out-bound migration [15]. The high in-migration rates in the more remote districts have been difficult to interpret [16], but are currently known to be driven by large-scale development projects and forest exploitation economies. The rapid rural development in Lao PDR is also attracting people from China, Vietnam, and Cambodia $[17,18]$, the majority of whom are employed by large private companies, live in unauthorized housing developments, and work as seasonal agricultural laborers or as informal forest workers. Many are unregistered or illegal, thus they try to avoid contact with authorities of any kind and are therefore reluctant to seek health care [2]. It is estimated that there are from 54135 [17] to 200000 [19] foreign workers, which is significant given a population of approximately seven million in 2013. The establishment of special economic zones and construction of Chinese markets in major towns suggest that the number of Vietnamese and Chinese migrants could be much higher than the reported figures [20]. Recent anecdotal reports from the Cambodia and Lao PDR border areas reveal that there is more active movement across both land (Dom Kralor-Voeung Kam) and riverine (Koh Chheuteal Thom) border crossing points.

\section{The current situation: challenges for the health system and strategies to addressing MMPs}

\section{Health care delivery in the community}

The main network for health care provision remains the public system with government owned and managed provincial and district hospitals and health centers/ clinics. At the village level, there are large numbers of village health volunteers (VHVs), members of community health committees, and traditional birth attendants (TBAs). Members of community health committees and village (zonal) committees are characterized by various health center management arrangements, health promotion activities, and communicable disease prevention campaigns, and are usually linked with staff from their local health centers.

In the period of 2009-2010, there were 53676 local community members involved in health activities, of whom 14 812 were VHVs, 6128 were TBAs, 1222 were traditional healers, and 31514 were members of village health committees [21]. Since 2013, village malaria volunteers and village malaria workers (paid incentives in malaria endemic villages) have played a key role in the distribution of longlasting insecticide-treated nets (LLINs), provision of early diagnosis and treatment (EDAT) through the use of rapid diagnostic tests and effective artemisinin-based combination therapy, and reporting of results to the nearest health center on a monthly basis in return for fresh supplies [22]. A scheme currently being initiated in the south expands the VHV and Village Health Worker community case management strategy to a specific focus on mobile populations (plantation workers, seasonal agricultural laborers, forest workers, etc.) [4] involved in all long-term and short-term development projects. 


\section{Malaria surveillance and response}

In 2012, malaria reporting forms were redesigned to simplify the process and improve the MIS. This resulted in some enhancement in the accuracy and timeliness of reporting due to the introduction of a cloud-based reporting system [4]. In 2015, MIS forms were revised to routinely disaggregate malaria patients' place of origin and travel history. However, the current approaches may still fail to capture malaria surveillance data on MMPs for a number of reasons, including, language barriers, legality status of work activities or residence, access to health facilities, capacity of health staff in data management, reporting, and use of information and technology (ICT) tools [23]. The Health Sector Reform Framework of the Ministry of Health aims to establish, as a key element, the District Health Information Software (DHIS2) as an ICT platform to strengthen health information systems across Lao PDR [4] with an integrated malaria, TB, and HIV program module that will require an optimum set of minimal essential data reporting to a set of indicators for each of the diseases [24]. While this effort is a positive achievement for health information systems in the country, in the context of malaria elimination efforts however, the capacity of individual case reporting at the health facility level and the conduct of timely case investigation as part of pre-elimination and elimination activities needs to be strengthened [25]. An added challenge is the need for relevant data on labor trends and development project databases from non-health sectors, i.e. Ministry of Natural Resources and Environment, Labor, and Energy/Mines, to be included and periodically updated in stratification of malaria risk areas. In addition, there needs to be adequate capacity to analyze these data to forecast health (malaria) trends and incorporate them into program strategy and implementation, as well as funding flexibility to respond to changes in disease trends [14].

\section{Case management and malaria drug resistance}

In Champasak, southern Lao PDR, the therapeutic efficacy of artemether/lumefantrine (Coartem ${ }^{\circ}$, the first-line treatment regimen) has been unaffected and cure rates have remained high since 2005. However, a trial conducted in two of the province's districts in 2013 reported that $22.2 \%$ of the patients treated with artemether/lumefantrine were still parasitemic on day 3 after treatment, with the presence of $\mathrm{K} 13$ mutations in the circulating parasite population. This confirmed the emergence of artemisinin resistance in southern Lao PDR [26]. These results come from therapeutic efficacy studies (TESs), where patients who are enrolled are those that can be followed up serially over the course of treatment and beyond for blood tests. The proportion of patients with delayed parasite clearance times are believed to be similar or even higher among the highly mobile populations who are excluded from the inclusion criteria of TES.

Plasmodium vivax currently accounts for almost 50\% of the malaria cases in southern Lao PDR and ongoing pilot studies in three sites to inform a nationwide introduction of primaquine is expected to be a core strategy to prevent the relapse of $P$. vivax infections while also acting as a radical cure for $P$. falciparum. If scaled up nationally, this could be the single most important factor for reducing transmission among returning mobile workers from the south, many of whom have repeated infections in a given year [CMPE, Summary report of the Inception Cross Border meeting for ICC2 Project, Champasak Province, Lao PDR 18-19 August 2016].

\section{Partnerships with the private sector}

After a 2005 drug use survey [27] revealed that 33\% $(172 / 521)$ of patients sought treatment from the private sector (defined as a private pharmacy, clinic or practitioner, drug seller, or mobile drug vendor), the national malaria program initiated a public-private mix (PPM) engagement with registered private pharmacies and clinics in September 2008. Initially, 141 private pharmacies and 9 registered clinics in four malaria endemic provinces were enrolled and trained to provide malaria diagnosis, treatment, and referral, with monthly reports to and periodic supervision from District Malaria Stations.. Following an evaluation, this initiative was geographically scaled up to a total of eight provinces, four of which are in the south of the country. Analysis of the data collected from January 2009 through to February 2013 suggests that the PPM project has contributed to about $7 \%$ of the total individuals who were tested in the eight provinces [4]. Micro-planning workshops during the malaria outbreaks in 2012 and 2013 identified and targeted an additional 149 pharmacies and drug vendor sites as a strategy to improve access to malaria services for high-risk mobile population in southern Lao PDR. Although the reporting forms used at these sites capture patients' place of origin, current reporting and routine surveillance forms and systems are unable, at higher levels of aggregation (provincial and central levels) to disaggregate patients' place of origin for analysis. However, the selection criteria of PPM sites are based partly on the preferred mode of access by MMPs in these areas [CMPE, unpublished, Evaluation of the PPM initiative in four PPM pilot provinces, October 2009]. There are immediate plans to expand the current PPM initiative to cover all registered private sector providers by 2018 [4].

\section{Vector control and personal protection among MMPs}

While notable attempts have been made since 2012 by the national program to address coverage of MMPs with LLINs, long-lasting insecticide-treated hammocks (LLIHs), 
and mosquito repellents, high-risk groups that do not have fixed addresses, families that are newly settled in a village, and forest goers in areas of new settlements are missed during the formal mass distribution. A recent survey in the south of Lao PDR, albeit limited in its sampling, revealed that $82 \%$ of MMPs used conventional and hammock untreated nets purchased from the market, while only $16 \%$ used LLINs distributed free of charge as part of the program. In addition, $26 \%$ preferred using mosquito coils, lotion, or spray repellents [5]. This suggests that user preferences and acceptance need to be taken into account when designing appropriate strategies for mobile populations and forest goers. Whilst there is currently a lack of evidence as to the effectiveness of LLIHs and repellents for forest goers in Lao PDR, it is nevertheless a current strategy used for mobile populations in targeted villages, along with raising awareness on the use of protective clothing and repellents when spending nights outdoors. In the meantime, malaria posts and malaria mobile teams that are planned to be established in hotspot areas along the Thailand, Cambodian, and Vietnamese borders will be stocked with Icon $\operatorname{Max}^{\circledR}$ (a sachet Kit for long-lasting treatment of mosquito nets) for impregnation of self-purchased untreated net used by forest goers [4].

\section{The military}

The Laotian military has yet to be fully engaged in terms of malaria prevention and case management despite the fact that it is a high-risk mobile population. Whilst positive attempts have been made to collaborate and coordinate with the Ministry of Defense (MoD) by the Center for Malariology, Parasitology, and Entomology (CMPE), a systematic programmatic and integrated approach for incorporating the military malaria control program into the national strategy is lacking. Efforts have been made to provide army doctors and medics with up-to-date training covering the current national guidelines, case management, prevention strategies, and the provision of insecticides. There is now also mutual interest to explore options around insecticide-treated uniforms and repellents, and establish a memorandum of agreement between $\mathrm{MoH}$ and MoD to address the problem of malaria among soldiers, including the sharing of information on malaria morbidity and mortality [4].

\section{Human resources}

Health service provision is constrained by serious weaknesses relating to human resources for health. Key issues include limited numbers of qualified health workers, inappropriate distribution of qualified staff among geographic and health system levels, low and underfunded salaries, lack of incentives (financial, training, personal development), and inadequate reimbursement of costs leading to poor morale and low productivity among staff.
Towards the end of 2013, the quota for the health workforce was increased by 4000 but most of these workers were deployed in cities and urban centers, thus resulting in little support for malaria services in remote areas [4].

Malaria elimination requires skillful staff in health facilities at all levels, however, the facilities that treat malaria currently are understaffed, which compromises the ability of the malaria program to detect and respond to outbreaks. The contrasting epidemiological dynamics between the northern and southern regions with an unequal human resource distribution within the vertical malaria program poses an even greater layer of complexity in being able to efficiently provide protection to the highest risk groups, including forest workers and soldiers [19].

\section{Laws and legal frameworks}

Numerous laws exist to safeguard the health and welfare of workers [28, 29] including migrant or foreign labor, as well as conditions for the employer [30]. However, in the context of malaria, the worksite areas are generally remote and lack access to health, education, and basic services. Thus, implementation and enforcement remains a challenge, with affected workers likely to be illiterate, belong to an ethnic minority group, and live in the poorest households.

In 2009, the government agreed to allow the formation of Lao non-governmental organizations (NGOs). This decision was believed to encourage the creation of a stronger civil society [31] and to champion the rights of migrants, amongst others reasons. A more detailed review on how this has progressed since then is warranted but beyond the scope of this paper.

\section{Conclusions}

Member countries committed to adopting the World Health Assembly Resolution WHA68.2 on the WHO Global Technical Strategy for Malaria 2016-2030 and the GMS elimination strategy 2015-2030 in May 2015. The Lao PDR's 2015-2020 National Strategy for Malaria Control and Elimination outlines the strategies to progressively roll out the elimination of all species of malaria in selected provinces. Lao PDR's prime minister has also signed the Declaration to Eliminate Malaria by 2030 in the Association of South East Asian Nations (ASEAN) Region at the 9th East Asia Summit. Although the challenges are numerous, the outlook is optimistic if efforts are made on a few critical fronts.

Firstly, bolder investment in social sector spending should be geared towards improving health service provision and utilization [4], ensuring equitable access to primary health care (including malaria) through efforts to achieve its universal health coverage targets. This should be extended to populations that are mobile or where accesses to health services are an obstacle either to physical access or to legal status of certain populations. In the case of 
malaria elimination, it is essential to reach all of the populations at risk, in particularly those in remote locations, as well as difficult to reach workplaces and migrant communities [3]. Integration of health services, decentralization, and restructuring should not translate to a diminishing quantity and quality of the workforce required to achieve malaria elimination targets. Raising government employment quotas, redistribution of tasks and health services, capacitydevelopment activities and cross-training of the healthcare workforce [14], recruiting national staff with international experience, and recruiting professionals from the private sector [32] are proposed options to ensure a health workforce dedicated to the implementation and reporting of malaria activities [4]. Whilst acknowledging the challenges of maintaining this cadre of volunteers and workers over time, support from civil society organizations can create an enabling environment for training, supportive supervision, and service delivery.

Secondly, although the current population movement to forested areas and development projects is economically and financially driven and cannot be entirely stopped, in parallel with efforts to increase access through innovative strategies considering the mobility patterns and preferred access to health services of MMPs, enforcement of existing regulations should be accelerated to protect the workers and local populations living in these outbreak areas. In the short term, a multisector provincial action plan needs to be developed with the involvement of relevant agencies in agriculture, forestry, labor, energy and mining, as well as local community organizations, local authorities, and the military. A prerogative of the provincial governor should be to mandate all companies and project developers registered with the province to appoint focal point/s for health-related issues. A relook on agreements and in particular the possibility of channeling tax revenues collected from private companies on land use and forestry-related activities towards health-related activities, including malaria control and its elimination, should be explored. The Provincial Health Department, in turn, could ensure all health investment in the province is aligned with a provincial health integration plan. At a higher level, the $\mathrm{MoH}$ should create a subcommittee within the National Emerging Infectious Diseases Coordinating Office (NEIDCO) established under the prime minister's office to oversee local government authorities to support policy and enforcement issues related to private sector project development in the provinces.

Thirdly, malaria elimination strategies will require cross-border cooperation with Lao PDR's neighboring countries. Introduction of bilingual malaria patient cards that contain essential malaria information to be shown at any health care facility supported by SMS or mHealth platforms [24] will contribute to strengthened malaria surveillance, exchange of real-time essential data, and index case investigation across borders or in selected twin cities (district-district or district-township) where there is a malaria burden.

Fourthly, the engagement with the private sector would be essential, especially in the timely and effective implementation of health and environmental impact assessments, with private sector companies engaged in development and extractive industries [14]. This engagement should extend beyond Corporate Social Responsibility (CSR) capacities and facilitate dialogue between the health and private for-profit sectors on how to balance economic opportunities associated with domestic (local) health needs, services, and equity issues [33, 34]. Ensuring health care coverage of the informal sector is the most difficult challenge. The PPM initiative in Lao PDR for EDAT holds a lot of promise and should be reviewed to possibly expand its policy on engagement with the non-formal or unregistered drug outlets and vendors with suitable incentives for accreditation and licensing. This expansion would also create complimentary sentinel surveillance sites for the detection of malaria outbreaks that could be missed in the public sector health facilities.

Fifthly, the Lao malaria control program currently largely relies on LLINs and, in cases of outbreaks, indoor residual spray $[2,3]$. Evidence shows, however, that limited levels of control are achieved with LLINs among highly mobile populations [35]. Existing and new interventions, which also target mosquitoes outside of human habitations, must be combined into integrated packages that control human exposure to mosquitoes at multiple points in the mobility pathway [36]. This may need innovative delivery mechanisms through social marketing approaches and the private sector rather than being fully reliant on the malaria vertical program [5]. The preference for conventional untreated nets (versus LLINs) and certain forms of mosquito repellents, especially in southern Lao PDR, also needs to be explored and appropriate strategies developed.

Sixthly, while acknowledging that timely access to malaria information and treatment, and availability of preventive and treatment services is of utmost importance to malaria control and elimination, some interventions need to be specifically tailored to the particular circumstances of these non-homogenous populations. These should factor in pathways of movement, seasonality and timing of departure, transit, and arrival of high-risk groups including short- and long-term forest workers, their accompanying families, MMPs, and the military. This needs to be done in collaboration with a broader involvement of civil society, local NGOs, and indeed by direct representation of people affected by malaria in in ensuring 'MMP sensitive' approaches and interventions are adopted depending on the mobility context and the acceptance of the population 


\section{Additional file}

Additional file 1: Multilingual abstracts in the five official working languages of the United Nations. (PDF $606 \mathrm{~kb}$ )

\section{Abbreviations}

API: Annual parasite incidence; CMPE: Center for malariology, parasitology, and entomology; EDAT: Early diagnosis and treatment; GMS: Greater Mekong Subregion; ICT: Information and communications technology; Lao PDR: Lao People's Democratic Republic; LLIH: Long-lasting insecticide-treated hammock; LLIN: Long-lasting insecticide-treated net; mHealth: Mobile health; MIS: Malaria information system; MMP: Mobile and migrant population; MoD: Ministry of defense; MoH: Ministry of health; NGO: Non-governmental organization; PPM: Public-private mix; SMS: Short messaging serviceTBA: traditional birth attendant; TES: Therapeutic efficacy study; VHV: Village health volunteer; WHO: World Health Organization

\section{Acknowledgements}

Initial thoughts and direction for this paper were based on valuable discussions with Prof. Dr. Peter Odermat of the Swiss Tropical Medicine and Public Health Institute, Basel University, Switzerland.

\section{Funding}

No funding support was received.

\section{Availability of data and materials}

Not applicable.

\section{Authors' contributions}

SK carried out the literature review and drafted the paper. DG carried out further literature reviews, provided guidance at all stages of writing, and edited drafts and the final paper. $\mathrm{BH}, \mathrm{OS}$, and $\mathrm{CK}$ assisted with the literature search and verification of data. All authors read and approved the final version of the paper.

\section{Authors' information}

SK is Deputy Director of the National Institute of Public Health, Ministry of Health, Lao PDR. DG is the WHO medical officer for the malaria and border health, emergency response to artemisinin resistance for the GMS based in the WHO country office, Bangkok, Thailand. BH is Director of the CMPE, Ministry of Health, Lao PDR. CK and OS are technical staff of the CMPE.

\section{Competing interests}

The authors declare that they have no competing interests. Deyer Gopinath was a staff member at the $\mathrm{WHO}$ at the time of writing of this paper. The views expressed in this publication are the author's and do not necessarily represent the decisions or policies of the WHO.

\section{Consent for publication}

Not applicable.

\section{Ethics approval and consent to participate} Not applicable.

\section{Author details}

National Institute of Public Health, Ministry of Health, Ban Kaognot, Samsenthai Road, Sisattanak District, Vientiane, Lao PDR. 'World Health Organization (WHO), Country Office, Nonthaburi, Thailand. ${ }^{3}$ Center for Malaria, Parasitology, and Entomology (CMPE), Ministry of Health, Vientiane, Lao PDR.

Received: 24 June 2016 Accepted: 13 March 2017 Published online: 25 April 2017

\section{References}

1. National Strategy for Malaria Control and Pre-Elimination 2011-2015, Lao PDR, July 2010

2. Lao People's Democratic Republic Ministry of Health National Strategy for Malaria Control and Elimination 2016-2030 (in draft).

3. Briggs M, Fukuda M, Shafique M. Evaluation of increases in reported malaria cases in the six southern provinces of Laos, 2011-2013., March 2013 (unpublished).
4. The Global fund website. GFATM Lao PDR malaria concept note. 2015. http://www.theglobalfund.org/en/portfolio/country/?loc=LAO. Accessed 22 Jan 2016

5. Preliminary results of the "Formative Assessment to Identify Mobile and Migrant Population Networks in South Laos Considered at Risk of Malaria Infection." Health Poverty Action, 6 April 2015 (unpublished).

6. World Bank. Lao PDR Development Report 2014: Expanding Productive Employment for Broad-Based Growth: http://www.worldbank.org/en/country/ lao/publication/lao-pdr-development-report-2014. Accessed 16 Oct 2015.

7. Ministry of Energy and Mines, Department of Energy Business; http://www. poweringprogress.org/new/power-projects/plan. Accessed 19 Oct 2015.

8. Laos: Energy and mining sector set to grow, April 2015, http://en. vietnamplus.vn/laos-energy-and-mining-sector-set-to-grow/75054.vnp. Accessed 19 Oct 2015

9. Schönweger O, Heinimann A, Epprecht M, Lu J, Thalongsengchanh P, 2012: Concessions and Leases in the Lao PDR: Taking Stock of Land Investments. Centre for Development and Environment (CDE), University of Bern, Bern and Vientiane: Geographica Bernensia. doi:10.13140/RG.2.1.3501.7047.

10. Phouxay $\mathrm{K}$, Malmberg G, Tollefsen A. Internal migration and socio-economic change in Laos. Migr Lett. 2014;7(1):91-104. Retrieved from http://www. tplondon.com/journal/index.php/ml/article/view/204. Accessed 21 Dec 2015.

11. Cui L, Yan G, Sattabongkot J, Cao Y, Chen B, Chen X, et al. Malaria in the greater Mekong subregion: heterogeneity and complexity. Acta Trop. 2012; 121:227-39.

12. Leebouapao L. Recent Economic Development Performance and Some Perspectives on Economic Development Strategy for 2020 Lao PDR. Conference Proceedings: International Conference on GMS 2020: Balancing Economic Growth and Environmental Sustainability Focusing on Food Water - Energy Nexus. 20 - 21 February 2012. Royal Orchid Sheraton Hotel and Towers Bangkok, Thailand. ISBN No: 978-616-90685-5-6. http://www. gms-eoc.org/uploads/resources/76/attachment/International\%20Conference \%20on\%20GMS\%202020\%20(full\%20proceedings\%20-large\%20file).pdf. Accessed 14 Nov 2015.

13. Gopinath D, Ortega L. Lessons learnt from WHO GMS border activities. Asia Pacific Malaria Elimination Network (APMEN) Business and Technical Meeting, Hoi Anh, Viet Nam, 24 - 27 March 2015. http://static1.1.sqspcdn. com/static/f/471029/26204133/1430962135980/Session+4_Gawrie_APMEN-+ Costing_apmen.pdf?token=qCQzG\%2FjHXJKYNH4eFdtCnTaGy5M\%3D. Accessed 12 Dec 2015

14. Gopinath D. Development projects, migration and malaria in the GMS Biregional Meeting on Healthy Borders in the GMS, 5-7 August 2013, Bangkok, Thailand. http://www.searo.who.int/thailand/news/dev_projects_ migration_malaria_gms_dr_deyer.pdf. Accessed 12 Dec 2015.

15. National Statistical Bureau Lao PDR. Population Census 2005. http://www. nsc.gov.la/en/PDF/update\%20Population\%20\%202005.pdf. Accessed 20 Nov 2015

16. Socio-economic analysis of the Lao PDR. An analysis based on the population and housing census. In: Section C: migration. 2005. http://www. laoatlas.net. Accessed 4 Oct 2015.

17. National Statistical Center, Lao PDR. Labour market (2007-2012). http://nsc gov.la/la/Labor2.php. Accessed 4 Oct 2015.

18. Asian Development Bank. Institutional document, Lao People's Democratic Republic: Energy sector assessment, strategy, and road map - 2013 Update. http://www.adb.org/sites/default/files/institutional-document/33914/files/ lao-pdr-energy-assessment-2013-update.pdf. Accessed 4 Oct 2015.

19. International Organization for Migration (IOM). https://www.iom.int/ countries/lao-peoples-democratic-republic (acts and figures last updated August 2014. Accessed 5 Oct 2015.

20. Phetsiriseng I. Gender Concerns In Migration In Lao PDR. Migration Mapping Study: A Review of Trends, Policy And Programme Initiatives. A Study Conducted for UNIFEM, Lao PDR. February 2007. http://apmrn.anu. edu.au/conferences/8thAPMRNconference/17. Gender\%20Concerns\%20in\%20Migration\%20in\%20Lao\%20PDR.pdf. (Accessed 8 Oct 2015)

21. Jönsson K, Phoummalaysith B, Wahlström R, Tomson G. Health policy evolution in Lao People's Democratic Republic: context, processes and agency. Health Policy Plan. 2014. doi:10.1093/heapol/czu017.

22. Phommanivong V, Thongkham K, Deyer G, Rene JP, Barennes H. An assessment of early diagnosis and treatment of malaria by village health volunteers in the Lao PDR. Malar J. 2010;9:347. doi:10.1186/1475-2875-9-347. 
23. Cox J, Sovannaroth S, Dy Soley L, Ngor P, Mellor S, Roca-Feltrer A. Novel approaches to risk stratification to support malaria elimination: an example from Cambodia. Malar J. 2014;13:371. doi:10.1186/1475-2875-13-371.

24. World Health Organization. Regional office for the South-East Asia. In: Mobile and migrant populations and malaria information systems. Geneva: WHO; 2015.

25. World Health Organization. Malaria elimination: a field manual for low and moderate endemic countries. Geneva: WHO; 2007.

26. The World Health Organization publications. Status report on artemisinin and ACT resistance, WHO, September 2015. 2015. http://www.who.int/ entity/malaria/publications/atoz/status-rep-artemisinin-act-resistancesept2015.pdf. Accessed 4 Dec 2015.

27. The Ministry of health FDD. Rational pharmaceutical management plus. In: Antimalarial drug use survey in Lao PDR, October 2005. 2005.

28. Ministry of Labour and Social Welfare, Lao PDR. Occupational Safety and Health (OSH) Master Plan, 2005. http://www.lo.org/wcmsp5/groups/ public/—ed_protect/— protrav/—safework/documents/policy/wcms_ 187798.pdf. Accessed 15 Nov 2015.

29. Lao PDR Law on Labour. Article 42. In: Protection of workers. 2006. http:// www.unesco.org/education/edurights/media/docs/ 35b83ea83a0a172fd321996ab9c72ec901af4e15.pdf. Accessed 15 Nov 2015.

30. The Law on Investment Promotion of 2009: Article 5, Article 69 Clause 3 and Clause 5, Article 70. Accessed from: Business and Human Rights in ASEAN A Baseline Study. http://hrrca.org/wp-content/uploads/2015/09/05. BHR-Lao-PDR.pdf pg. 167. Accessed 15 Nov 2015.

31. Decree 115/PM on Associations, April 29, 2009, Lao PDR. http://www.iccsl.org/ pubs/lao_pdr_decree_law_on_associations.pdf. Accessed 15 Nov 2015.

32. Ahmed S, Annear PL, Phonvisay B, Phommavong C, Cruz Vde O, Hammerich A, Jacobs B. Institutional design and organizational practice for universal coverage in lesser-developed countries: challenges facing the Lao PDR S. Soc Sci Med. 2013;96:250-7. doi:10.1016/j.socscimed.2013.01.019.

33. Annear P, Nossal SA. Institutional strengthening for universal health coverage in the Lao PDR: barriers and policy options. Institute for Global Health. NUMBER 19, JULY 2012. http://ni.unimelb.edu.au/hphf-hub/ publications/workingpapers/institutional_andoperitional_barriers_to strengthening_universal_coverage_in_the_lao. Accessed 18 Nov 2015

34. Kanchanachitra C, Lindelow M, Johnston T, Hanvoravongchai P, Lorenzo FM, Huong NL, Wilopo SA, dela Rosa JF. Human resources for health in southeast Asia: shortages, distributional challenges, and international trade in health services. Lancet. 2011;377(9767):769-81. doi:10.1016/S01406736(10)62035-1.

35. World Health Organization, Regional Office for South-East Asia. Vector control and personal protection of migrant and mobile populations in the GMS: a matrix guidance on the best options and methodologies. New Delhi: World Health Organization; 2015. http://www.who.int/iris/handle/ 10665/204341

36. Smith C, Whittaker M. Beyond mobile populations: a critical review of the literature on malaria and population mobility and suggestions for future directions. Malar J. 2014;13:307. doi:10.1186/1475-2875-13-307.

\section{Submit your next manuscript to BioMed Central and we will help you at every step:}

- We accept pre-submission inquiries

- Our selector tool helps you to find the most relevant journal

- We provide round the clock customer support

- Convenient online submission

- Thorough peer review

- Inclusion in PubMed and all major indexing services

- Maximum visibility for your research

Submit your manuscript at www.biomedcentral.com/submit

) Biomed Central 